\title{
Apatit - Wollastonit Biyoaktif Cam Seramiklerde Kristalizasyonun Kırılma Tokluğu Üzerine Etkisi
}

\author{
${ }^{1}$ Erhan İbrahimoğlu, ${ }^{2}$ Zafer Tatlı, ${ }^{3}$ Fatih Çalışkan \\ 1,2,3 Sakarya Uygulamalı Bilimler Üniversitesi, Teknoloji Fakültesi, Metalurji ve Malzeme Mühendisliği Bölümü \\ Esentepe Kampüsü, Sakarya, Türkiye
}

\begin{abstract}
Özet
Biyomalzemeler, canlı dokuları desteklemek ya da tedavi etmek için kullanılan doğal ya da sentetik malzemeler olarak tanımlanırlar. Bir biyomalzeme için en önemli özelliklerin başında biyouyumluluk gelmektedir. Kısaca, biyomalzemenin kemik doku ile kimyasal bağ yapması istenmektedir. Bu amaçla da biyoaktif malzemeler geliştirilmiştir. Bu çalışmada da biyoaktif bir malzeme olan apatit - wollastonit esaslı malzemenin, tamamen amorf olarak cam fazında üretimi yapılmış ve malzeme sonrasında mekanik özelliklerini geliştirmek için yaklaşık $1100^{\circ} \mathrm{C}$ civarlarında kristalize edilmiştir. Kristalize olan cam seramik yapılı bu malzemenin mekanik özellikleri incelenmiş ve herhangi bir ısıl işlem görmemiş olan cam yapıdaki numuneyle karșılaştırılmıștır. Mekanik özelliklerin belirlenmesinde ilk olarak vickers yöntemiyle mikrosertlik ölçümü yapıllmış ve oluşan izden yararlanarak indentasyon tekniği ile malzemenin kırılma tokluğu hesaplanmıştır. Sonuçlar incelendiğinde amorf yapıdan kristalize olan numunenin sertliğinde hafif bir artış gözlemlenmiştir. Bununla birlikte seramik yapılı malzemelerin kullanımını arttıracak en önemli özellik olan kırılma tokluğu kristalizasyon işlemi ile oluşan tanesel yapıdan güçlü bir şekilde etkilenerek kıyas numunesinde yaklaşık \% $75^{\prime}$ 'lik bir kırılma tokluğu değerinde artış göstermiştir.
\end{abstract}

Anahtar Kelimeler: Apatit wollastonit, biyoaktif, kırılma tokluğu, kristalizasyon.

\section{Effect of Crystallization on Fracture Thoughness in Apatite - Wollastonite Bioactive Glass Ceramics}

\author{
${ }^{1}$ Erhan İbrahimoğlu, ${ }^{2}$ Zafer Tatlı, ${ }^{3}$ Fatih Çalışkan \\ ${ }^{1,2,3}$ Sakarya University of Applied Science, Faculty of Technology, Department of Metallurgy and Material \\ Engineering, Esentepe Campus, Sakarya, Türkiye
}

\begin{abstract}
Biomaterials are defined as natural or synthetic materials used to support or treat living tissues. One of the most important properties for a biomaterial is biocompatibility. Briefly, biomaterials are required to have a chemical bond with bone tissue. Bioactive materials have been developed for this purpose. In this study, apatite - wollastonite based material, which is a bioactive material, was produced to consist entirely of amorphous phase and the material was crystallized around $1100^{\circ} \mathrm{C}$. The mechanical properties of this crystalline material were investigated and compared with the unheattreated glass material. In the determination of mechanical properties, firstly microhardness measurement was made by vickers method and the fracture toughness of the material was determined by indentation technique using the trace. In conclusion, when the results were examined, a slight increase was observed in the hardness of the sample crystallized from the amorphous structure (glass-ceramics). However, fracture toughness, which is the most important feature to increase the use of ceramic materials, was strongly influenced by the granular structure formed by the crystallization process and showed an increase in fracture toughness value of approximately $75 \%$ in the comparative sample.
\end{abstract}

Keywords: Apatite wollastonite, bioactive, fracture toughness, crystallization.

\footnotetext{
*Corresponding author: Address: Faculty of Technology, Department of Metallurgical and Materials Engineering, Sakarya University of Applied Sciences, 54187, Sakarya TURKEY. E-mail address:

erhanibrahimoglu@subu.edu.tr, Phone: +902646160290
} 


\section{Giriş}

Biyoseramikler, insan vücudundaki canlı dokuların görevlerini yerine getirmek amacıyla kullanılan, aynı zamanda sürekli veya belli aralıklarla vücut sıvılarıyla temas halinde bulunan seramik yapılı malzemelerdir. Bir başka deyişle biyoseramikler, kas - iskelet sisteminin zarara uğramış bölümlerinin tamiri ve yeniden yapımı için kullanılan seramikler olarak da tanımlanabilir [1].

Bir biyoseramik, canlı vücuduna implante edildiğinde vücutta malzemeye karşı bir takım reaksiyonlar gelişir. $\mathrm{Bu}$ dokunun malzemenin karakteristiğine göre ona uyguladığı davranışıdır. $\mathrm{Bu}$ davranış biyoseramikler için biyoinert ve biyoaktif olarak tanımlanmaktadır. Biyoinert olan malzemeler, doku içerisinde toksik etkiler barındırmamasına rağmen doku ile sıkı kimyasal bağlar oluşturmazken, biyoaktif olanları kemik dokusuna benzerliklerinden kaynaklı yapısı gereği sıkı bağlar oluşturmaktadır[2]. Biyoaktif cam ve cam seramikler, biyoseramiklerin bir türü olup, cam olanları amorf yapıda iken, cam seramik olanları amorf yapının içerisinde kristal fazların da bulunduğu malzemelerdir [3,4]. Biyoseramikler incelendiğinde, seramiklerin karakteristik özelliklerinden kaynaklanan ve bu malzemelerin yapısı gereği darbe, eğme gibi kuvvet bileșenlerine maruz kaldığında ve kırılma tokluğu bakımından zayıf kaldıklarından implant malzemesi olarak kullanımında önemli handikapları göze çarpmaktadır. Ancak yine seramiklerin karakteristik bir özelliği olarak basma mukavemetleri yüksektir. Bu da kimi biyolojik uygulamalar için avantaj teşkil edebilir [5].

İdeal olarak, klinik uygulamalar için geliştirilen biyoaktif implantlar, konak dokunun mekanik özelliklerine uymalı ve sert ve / veya yumuşak dokularla güçlü arayüzey bağları oluşturmalıdırlar [6]. "Sert" kemik dokusuna nispeten yakın fiziksel özelliklere sahip olan biyoaktif camların inorganik yapısı ve mekanik özellikleri göz önüne alındığında, kemik ve diş dokusun ile implantın temas halinde kullanılmasına büyük önem verilmiştir. Bu konudaki çalışmalar, cam yapısı içerisinde kristal oluşumlar gerçekleştirilmek ve çeşitli katkılar yapmak suretiyle mekanik özelliklerin geliştirilmesi üzerine yoğunlaşmıştır [7]. Biyoaktif cam seramikler, kristal yapıdaki bağların güçlüğü nedeniyle mekanik mukavemet, sertlik ve termal genleşme gibi özellikler bakımından amorf cama kıyasla daha üstün özelliklere sahiptir. [8]. Bu malzemeler gerek biyoaktiflik gerekse mukavemet bakımından diğer biyomalzemelere göre de üstün özelliklere sahiptir [9].

Bu çalışmada, ergitme yöntemiyle üretilmiş olan apatit wollastonit biyoaktif malzeme hızlı soğutularak cam formuna getirilmiş ve kristalizasyon 1 sıl işlemine tabi tutularak cam seramik haline getirmek suretiyle kırılma tokluğu geliştirilmeye çalışılmıştır.

\section{Materyal ve Metot}

Apatit wollastonit için, $\mathrm{CaO}, \mathrm{SiO}_{2}, \mathrm{P}_{2} \mathrm{O}_{5}, \mathrm{MgO}, \mathrm{Al}_{2} \mathrm{O}_{3}$, ve $\mathrm{CaF}_{2}$ bileşikleri kullanılarak bir karışım hazırlanmış ve hazırlanan karışım $1400^{\circ} \mathrm{C}$ 'nin üzerinde 1 saat boyunca ergitilerek grafit kalıplar içerisinde hızlı soğutularak amorf yapılı transparan cam ürünler elde edilmiştir. Daha sonra bu cam yapıdaki malzemeler, max. $1300^{\circ} \mathrm{C}^{\prime}$ lik standart 1 sıl işlem fırınında 1 saat süreyle $1100^{\circ} \mathrm{C}$ 'nin üzerinde çekirdekleşmesi ve kristal büyüme aşamalarına imkan vermek için kristalizasyon 1sıl işlemine tabi tutulmuştur. Bu işlemin 1sıl işlem döngüsü Şekil 1'de gösterilmiştir.

Daha sonra numunenin mekanik özelliklerinin tespiti için sertlik ölçümleri yapılmış ve buna bağlı olarak indentasyon tekniğiyle kırılma toklukları hesaplanmıştır. MikroVickers sertlik ölçümü ve çatlak boyu ölçümü yapılarak ilgili formül yardımıyla kırılma tokluk değerleri hesaplanmıştır. Üretilen numunelerin kimyasal yapılarını belirlemek ve kristalizasyon kinetiğini ortaya çıkarmak için malzemeler X-Işını Kırınım analizine tabi tutulmuştur. 


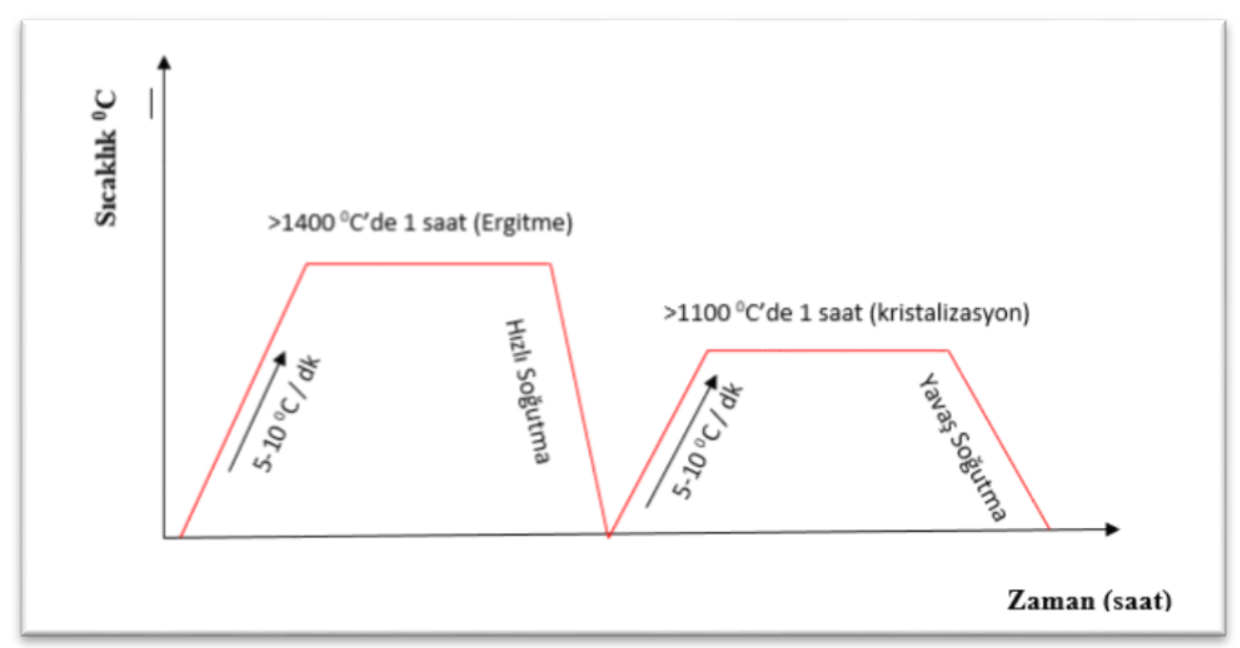

Şekil 1. Kristalizasyon isıl işlemi.

\section{Sonuçlar ve Tartışma}

\subsection{XRD Sonuçları}

Üretilen transparan görünümlü cam numuneler ve kristalizasyon sonrası opaklaşan numunelerin XRD analiz sonuçları Şekil 2'de verilmiştir. XRD pikleri incelendiğinde amorf fazlar ve kristalin yapıları görülmektedir. Isıl işlem görmemiş doğrudan amorf fazdan hızlı soğutularak üretilen malzemede herhangi bir kristalin faz tespit edilememiştir. Bu da hedeflenen \%100 cam fazının elde edildiğini ispatlamaktadır. Bu sonuç camsı yapılı malzemelerin karakteristik özelliklerinden olan ve üretilen 1 sıl işlem görmemiş numunenin transparan görünüm uyumludur. Kristalizasyon 1sıl işleminden sonra elde edilen numune de ise wollastonit ve florapatit fazları görülmüştür. Bu sonuç cam numunenin cam-seramik malzemeye dönüştüğünü göstermektedir.

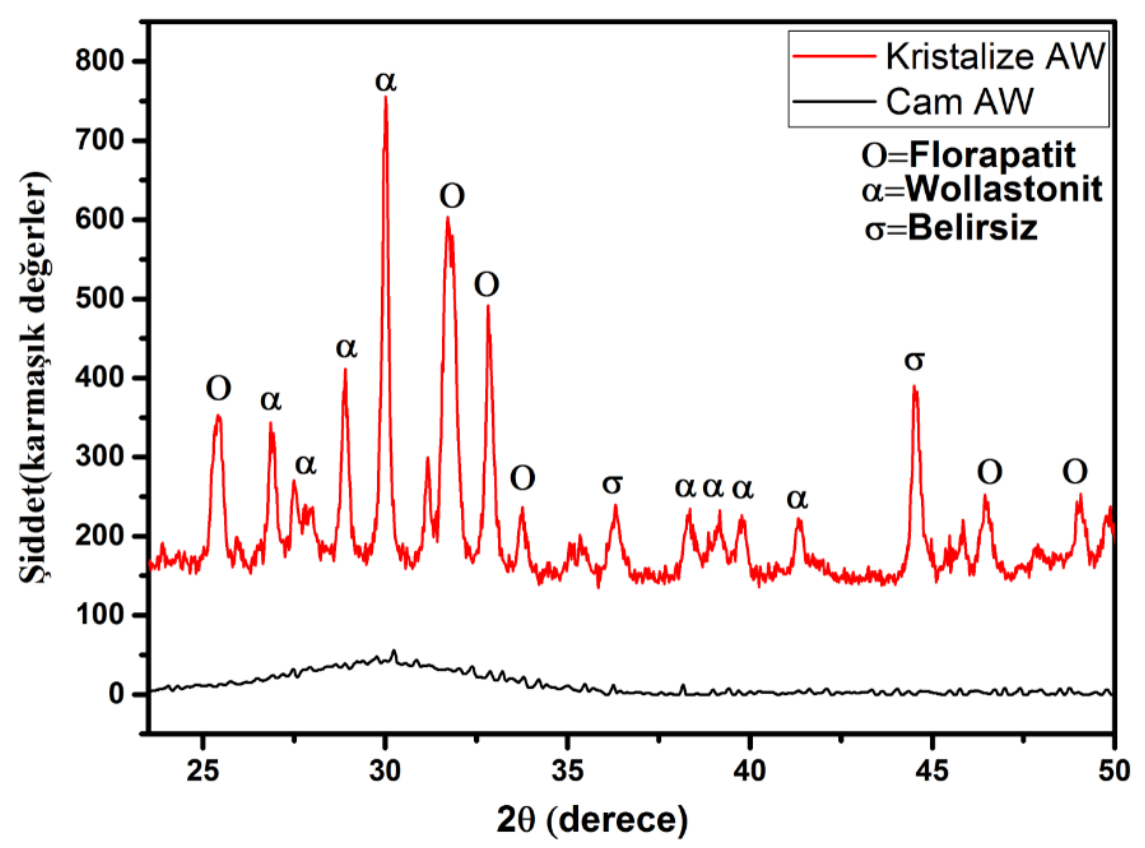

Şekil 2. Cam AW ve kristalize AW numunelerinin XRD analizi 


\subsection{Mekanik Özellikler}

Mekanik özelliklerin tespiti için malzemede mikroVickers sertlik ölçümleri ve indentasyon metoduyla kırılma tokluğu hesabı yapılmıştır. Kırılma tokluğu hesaplanırken kullanılan indentasyon tekniğinden elde edilen verilerin yerleştirildiği denklem (1) aşağıda verilmiştir.

$$
K c=\frac{\mathrm{Hv} \cdot \mathrm{k} \cdot 0,15 \cdot \sqrt{\mathrm{a}} \cdot(\mathrm{C} / \mathrm{a})^{-3 / 2}}{\mathrm{I}}
$$

Burada Kıc: kırılma tokluğu, Hv: vickers sertlik değeri, a: izin yarısı (d/2), c: çatlak boyu, k: düzeltme faktörü (C/a için yaklaşık 3,2), I: sabit (3) ifade etmektedir.

MikroVickers sertlik (Şekil 3) ve kırılma tokluğu (Şekil 4) sonuçları aşağıdaki grafiklerde gösterilmiştir.

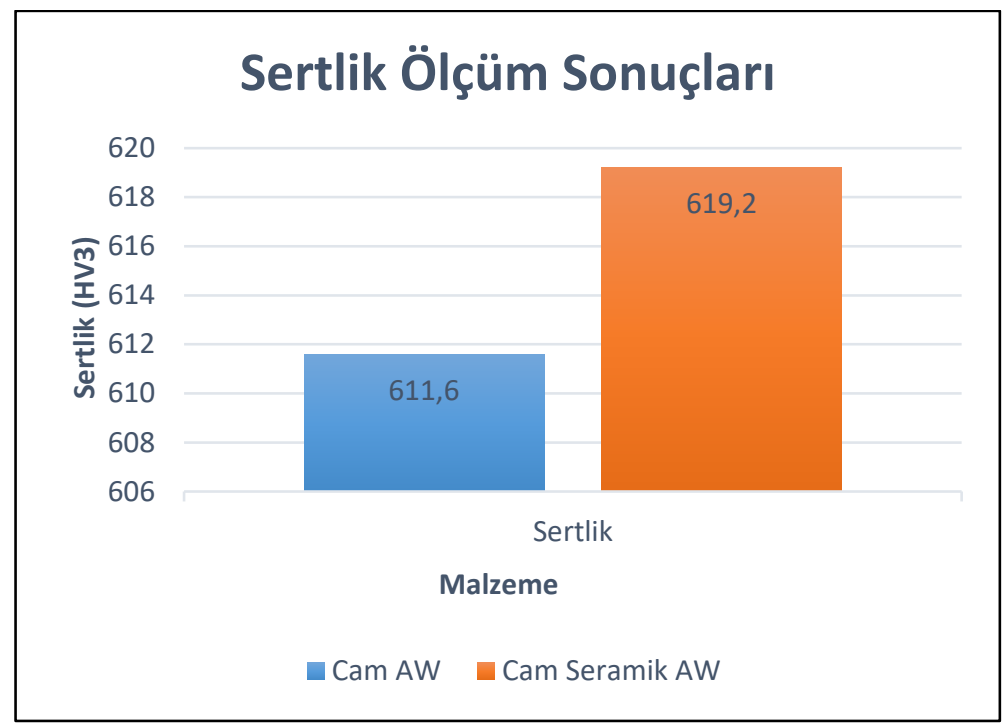

Şekil 3. Cam AW ve Cam Seramik AW numunelerinin mikroVickers sertlik sonuçları

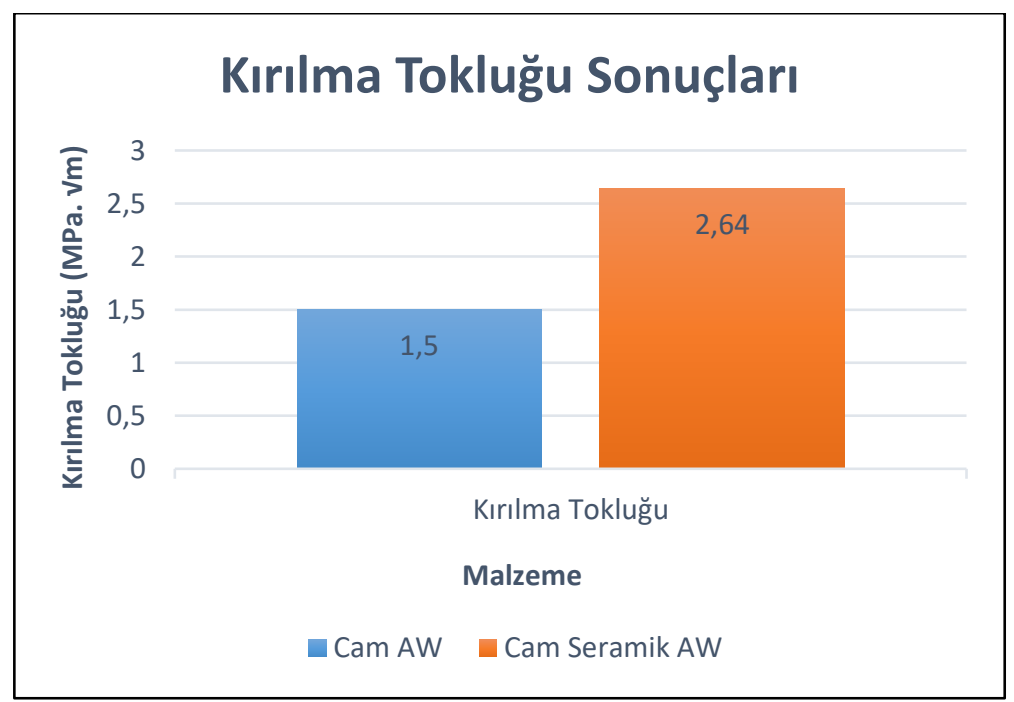

Şekil 4. Cam AW ve Cam Seramik AW numunelerinin kırılma tokluğu grafiği 
Şekil 3'teki grafik incelendiğinde, cam numunede sertlik değeri 611,6 HV3 olarak ölçülmüştür. Kristalizasyon işleminden sonra tanesel bir yapıya sahip olan cam-seramik malzeme de ise 619,2 HV3 seviyelerine çıkmıştır. Sertlik değerinde az miktarda bir iyileşme gözlenmiştir.

Literatür çalışmalarına bakıldığında yapıda kristal fazların artmasıyla paralel olarak mekanik özelliklerde de gelişme sağlandığı bildirilmişstir. Bu bakımdan çalışma literatür ile uyumludur. $[10,11]$ Mikroyapı görüntüleri incelendiğinde alümina fazının malzemeden dekompoze olduğu görülmüştür. Yapılan çalışmalarda yine yapı içerisinde alüminanın yer alması mekanik özelliklerde ve kimyasal kararlılıkta artış sağladığı bildirilmiştir $[12,13]$.

Şekil 4’te verilen kırılma tokluğu grafiğine bakılırsa sertlik sonuçlarına paralel olarak CamSeramik AW numunesi kırılma tokluğunda da 1,5 Mpa. $\sqrt{\mathrm{m}}$ civarından yaklaşık 2 katına yükselmiştir. $2.64 \mathrm{Mpa} . \sqrt{\mathrm{m}}$ değeri cam seramikler için ortalamanın üzerinde kabul edilebilir. (LAS cam seramiklerinde $2.29 \mathrm{Mpa} . \vee_{\mathrm{m}}$, mika cam seramikleri $1.74 \mathrm{Mpa} .{ }_{\mathrm{m}}$, demir zengini atıklardan üretilen cam seramikler 3.75 Mpa. $\sqrt{\mathrm{m}})[14,15]$.

\section{Tartışma}

Bu çalışmada ilk olarak, cam ergitme metodu ile ergitme sonucu kalıplanan numunelerin kritik soğuma sıcaklığını aşmadan başarıyla AW bileşenlerini içeren kristallenmemiş tamamen amorf yapılı cam ürünlerin üretimi başarılmıştır. Bu durum XRD analizi ile kanıtlanmıştır.

Cam AW ürünlere yapılan ısıl işlemler ile yapının çekirdeklenme ve sonrasında kristal büyümesi sonucu kristalize olmuş bir cam-seramik üretiminin başarılabilmiştir. Malzemede kristalizasyonla yani cam seramik yapısı elde edildiğinde mekanik özelliklerde literatürle paralel olarak artış olduğu gözlemlenmiştir $[12,13]$. Sertlik üzerinde çok büyük değişiklikler gözlenmezken, kırılma tokluğunda güçlü bir artış (yaklaşık 2 kat) söz konusu olmuştur. Bu artışın sebebi olarak kristal yapıların oluşmasının yanında alüminanın dekompoze olarak yapıda çökelti şeklinde bulunmasının önemli katkısı olduğu düşünülmektedir. Dolayısıyla alümina içeren A-W cam seramiklerde mekanik özellikler kristal fazlar ve mikroyapıdan önemli ölçüde etkilenmektedir.

Sertlik seramiklere ait bilinen bir üstünlük olsa da en büyük handikapı kırılma tokluğunun düşük olmasıdır. Dolayısıyla bu çalışmada Kıc değerlerindeki artış AW cam seramiklerin insan vücudundaki sert doku implant uygulamalarında daha güvenilir olarak kullanımında kayda değer bir gelişmedir.

\section{Referanslar}

[1]. Kayan, S., et al.“Apatit Wollastonit Cam Seramik ile Gözenekli Biyoalzeme Üretimi”, Sakarya Üniversitesi, Teknoloji Fakültesi, 2014.

[2]. Hench, L.L., et al."Bioactive Ceramics: Theory and Clinical Applications", 7th International Symposium on Ceramics in Medicine, Turku, Finland, July 1994. 
[3]. Best, S.M., et al. "Bioceramics: Past, present and for the future", Journal of the European Ceramic Society 28 (2008) 1319-1327.

[4]. Ramahan, M., et al."Bioactive glass in tissue engineering", Acta Biomaterialia 7 (2011) $2355-2373$.

[5]. Timuçin, M., et al.“Apatit Wollastonit Biyoaktif Seramiklerin Üretimi ve Karakterizasyonu”, Tübitak Projesi, Ankara, Mayıs, 2008.

[6]. Kaur, G., et al."Mechanical properties of bioactive glasses, ceramics, glass-ceramics and composites: State-of-the-art review and future challenges", Materials Science \& Engineering C 104 (2019) 109895.

[7]. Apel, J.P., et al. "Phenomena and mechanisms of crack propagation in glass-ceramics", J. Mech. Behav. Biomed. Mater. 1 (4) (2008) 313-325.

[8]. Thompson, I.D., et al."Mechanical properties of bioactive glasses, glassceramics and composites", Proceedings of the Institution of Mechanical Engineers, Part H: J. Engg. Med. (Proc Inst Mech Eng H) 212 (2) (1998) 127-136.

[9]. Timuçin, M., et al."Apatit Wollastonit Biyoaktif Seramiklerin Üretimi ve Karakterizasyonu”, Tübitak Projesi, Ankara, Mayıs, 2008.

[10]. Park, J., et al. “Tribological properties of $\mathrm{MgO}-\mathrm{CaO}-\mathrm{SiO} 2-\mathrm{P} 2 \mathrm{O} 5-\mathrm{F}-$ based glass-ceramic for dental applications”, Materials Letters 61 (2007) 1916-1921.

[11]. Ercenk, E., et al."The crystallization kinetics of the $\mathrm{CaO}-\mathrm{SiO} 2-\mathrm{P} 2 \mathrm{O} 5-\mathrm{MgO}-\mathrm{A} 12 \mathrm{O} 3$ base glass system”, Journal of Non-Crystalline Solids 387 (2014) 101-106.

[12]. Park, J., et al.“Bioceramics: Properties, Characterizations, and Applications”, Springer, 2008.

[13]. Park, J., et al."Tribological behavior of alumina-added apatite-wollastonite glassceramics in simulated body fluid", Materials Chemistry and Physics 124 (2010) 113-119.

[14] Quinn GD, et al."Swab JJ, Patel P. Fracture toughness of modern and ancient glasses and glass ceramics as measured by the SEPB method." Ceram Eng Sci Proc. 2019;39(2):1-13.

[15] Han, W., et al."Glass ceramic of high hardness and fracture toughness developed from iron-rich wastes”, Acta Metall. Sin. (Engl. Lett), 22 (2009), 181-190. 